\title{
A Review of Anesthesia Simulation in Low-Income Countries
}

\author{
Oleg Turkot $^{1} \cdot$ Michael C. Banks ${ }^{1} \cdot$ Seung Woo Lee ${ }^{1} \cdot$ Adam Dodson $^{1} \cdot$ Shirley Duarte ${ }^{1} \cdot$ Mwemezi Kaino $^{2}$. \\ Howard Nelson-Williams ${ }^{1} \cdot$ Serkan Toy ${ }^{1} \cdot$ John Sampson ${ }^{1}$
}

Published online: 28 February 2019

(C) The Author(s) 2019

\begin{abstract}
Purpose of Review Anesthesia workforce gaps in low- and middle-income countries (LMICs) can hinder safe surgical care. Several countries have fewer than one anesthesiologist per million population and some have fewer than two anesthesiologists nationally. Limited apprenticeship opportunities and inadequate supervision present serious challenges in these locations. Although simulation training could help disseminate expert guidance, the high cost, technical challenges, and varied approaches limit application. We reviewed the literature on cost-efficient and effective simulation training programs for anesthesia workforces in LMICs.

Recent Findings Publications relevant to anesthesia simulation in these countries are limited but include anesthesia skill gap identification, technical skill training, and scenario management.

Summary High-cost, high-technology simulation available in high-resource countries is often impractical in LMICs. We identified low-cost approaches that are typically used to assess skill deficiencies and develop nontechnical and technical skills. Future studies should evaluate optimal modalities and equipment for greatest impact.
\end{abstract}

Keywords LMIC $\cdot$ Africa $\cdot$ Training $\cdot$ Safe surgery $\cdot$ Nurse $\cdot$ Critical care

\section{Introduction}

Over 5 billion people lack access to safe and affordable surgical anesthesia and obstetric (SAO) care [1]. Most live in low- and middle-income countries (LMICs) [2]. SAO care is important to public health because it is paramount to the prevention of death and disability and to the development of a resilient health care system [3]. Population density data have shown that many countries in sub-Saharan Africa and South-East Asia have fewer than 1 anesthesia provider per 100,000 population (Fig. 1). Studies indicate that an SAO workforce density of 20 to 40 per 100,000 significantly improves health outcomes [4].

This article is part of the Topical Collection on Global Health Anesthesia

John Sampson

jsampso4@jhmi.edu

1 Department of Anesthesia and Critical Care Medicine, Johns Hopkins Hospital, 600 Wolfe St/ Phipps 415., Baltimore, MD 21287 , USA

2 Chair of Anesthesia and Intensive Care, Kilimanjaro Christian Medical Centre, Moshi, Tanzania
The shortage of anesthesia providers among the SAO workforce limits optimal care and jeopardizes patient outcomes. In many sub-Saharan African countries, the ratio of health care providers in the population can be less than one anesthesiology physician per million, with some countries having as few as zero to three anesthesiologists nationally. SAO care in these locations relies heavily on task-shifted nurse anesthetists, anesthesia officers/technicians, or physicians and nurses who are informally trained in anesthesia delivery. The lack of anesthesia experts in these countries constrains the apprenticeship, supervised guidance, and continuing medical education opportunities for taskshifted nurse anesthetists. These circumstances hinder fundamental anesthesiology training and practice improvement, especially in aspects of clinical decision-making and technical and nontechnical skill development.

LMICs represent $48 \%$ of the world's population and have only $20 \%$ of the SAO workforce (19\% of the surgeons, $15 \%$ of the anesthesiologists, and $29 \%$ of obstetricians) [5]. Training and education can help to increase the density of the SAO workforce as well as identify and remediate critical skill and process gaps among current practitioners in LMICs. Training opportunities can be increased through private and nongovernmental organiza- 


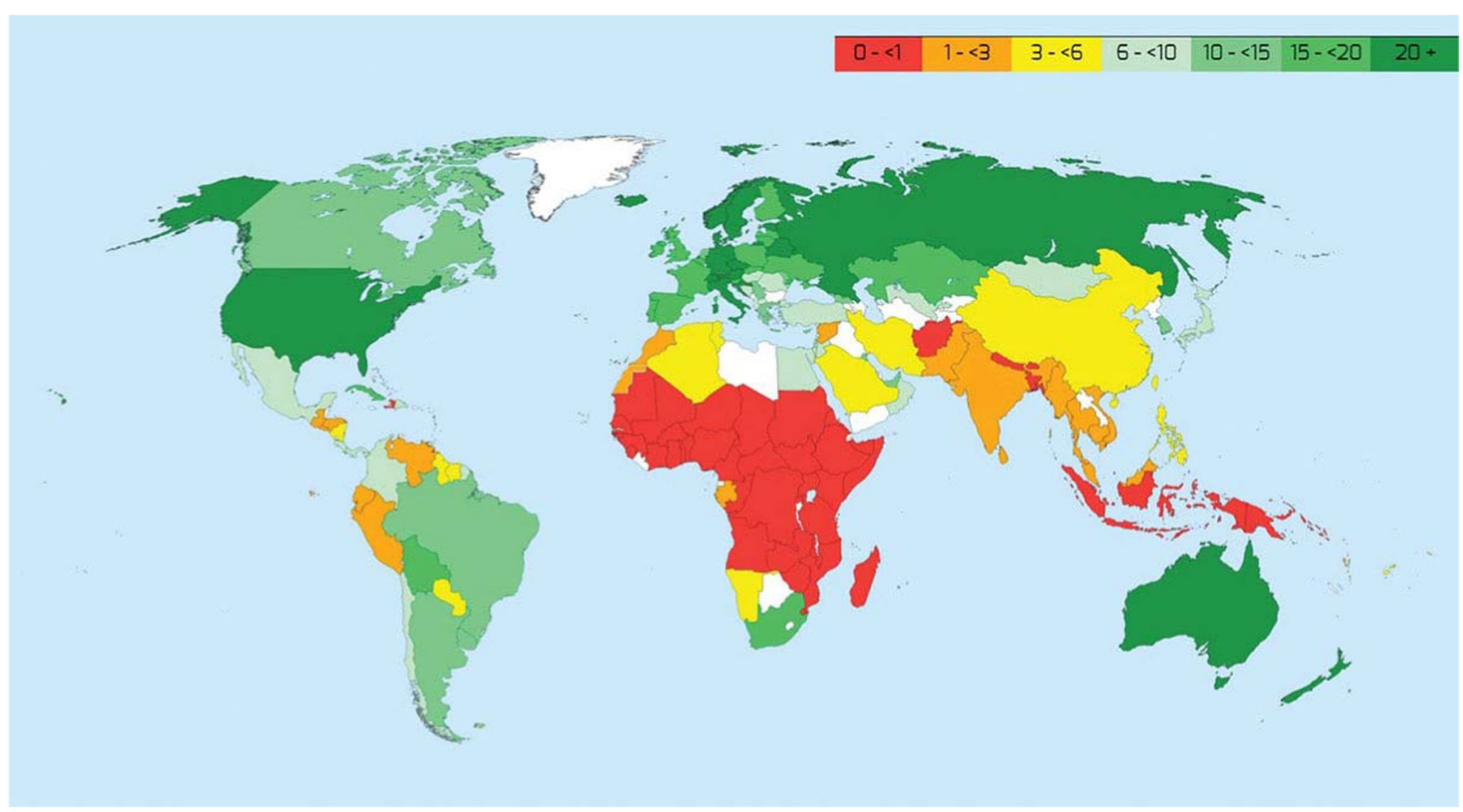

Fig. 1 Global distribution of physician anesthesia providers per 100,000 population. Source: The World Federation of Societies of Anaesthesiologists (WFSA) Global Anesthesia Workforce Survey [60]

tion educators and partnerships between high-income countries and LMICs.

Simulation is an important training method that has been used successfully in some LMICs. Examples include the partnership between Canadian and Rwandan governments that resulted in the creation of a simulation center to teach SAO clinical skills [6]. Another example is found in Tanzania where the University of California, San Francisco, partnered with the School of Medicine at Muhimbili University of Health and Allied Sciences. Simulation was used to train 60 senior medical students in fundamental SAO knowledge and skills, enabling them to assist with surgical procedures in a resource-limited environment [3]. In Mozambique, the Royal College of Surgeons in Ireland has collaborated with the College of Surgeons of East, Central, and South Africa to develop a van-based mobile simulation center that provides intubation and resuscitation training opportunities, although it is largely focused on laparoscopic surgery training [7].

Simulation-based medical education (SBME) offers a limited number of experts within a large geographic region, the opportunity to assess critical life-determinant anesthesia skills, and develop curricula and scenarios to target high-risk but uncommonly occurring critical events [8••]. SBME can help the SAO workforce to respond to these events through mastery learning [9] and/or Rapid Cycle Deliberate Practice (RCDP), a method in which the simulation facilitator can pause the simulation at teaching moments, provide immediate feedback and debriefing, and then rewind and try again
[10-12]. However, given the limited resources in some of these countries, a variety of barriers might inhibit implementation of these types of training modalities.

\section{Simulation and Logistical Challenges}

The foundation of simulation is influenced by adult learning theory and the work of Malcolm Knowles, who coined the term andragogy: the study of how adults learn [13]. Several adult learning theories that directly apply to simulation include David Kolb's experiential learning theory [14] and Jack Mezirow's transformational learning process [15]. The key step in both theories is that the learner must reflect on his/her experience. During simulation, reflection is the debriefing session when the learner and facilitator review the scenario. This is the period when learning occurs. After the debriefing, the learner can develop a new mental model or frame of reference upon which he/ she can experiment through simulation [16].

Simulation as an educational tool was first developed for medical use in 1969 by educator Stephen Abrahamson, PhD; anesthesiologist Judson Denson, MD; and psychologist Richard Wolfe, PhD [17]. Over the last two decades, simulation-based training has gradually become a significant component of medical education at undergraduate, graduate, and continuing medical education levels primarily in the highincome countries. The concerns for patient safety have constrained the opportunities to teach necessary clinical skills in actual clinical environments, which accelerated the need for 
simulation training programs [18-20]. SBME can offer a safe and effective learning environment as it provides "repetitive practice, ability to integrate into curriculum, ability to alter the degree of difficulty, ability to capture clinical variation, immediate feedback, and approximation of clinical practice" [20]. Two meta-analyses indicated that simulation-based training was associated with increase in learners' satisfaction, knowledge, and skills and was superior to other more traditional instructional methods in a wide range of topics: technical skills, communication, teamwork, and leadership [21, 22]. Simulation exercises also enable instructors to assess clinical performance [23•]. Simulation can be used to teach teamwork, identify system issues, or for just-in-time training. Simulation offers learners the opportunity to practice the tenets of interprofessional collaboration: communication, teamwork, roles/ responsibilities, and ethics [24].

Simulation has been shown to improve skills acquisition. In a study by Scavone et al. [25], residents who had focused training on a simulator for cesarean delivery with general anesthesia performed better on this task than residents who did not undergo focused simulator training [26]. Simulation can also be used to assess the work environment. In a study by Chima et al. [8・0], nurse anesthetists using a spontaneously breathing simulation manikin in a low-resource setting were identified as having numerous, unexpected gaps in knowledge and skills that could have resulted in a life-threatening situation for patients requiring general anesthesia for a cesarean section after spinal anesthesia placement was ineffective in providing a surgical spinal block. Once such endemic problems are identified, simulation-based training programs can be developed that target the process, knowledge, and procedural gaps.

Simulation can be used not only to teach technical skills but also nontechnical skills such as effective communication and task management. One example is the anesthesia nontechnical skills (ANTS) framework, which has been proposed as a way to develop a simulation-based curriculum in low-resource countries. Originally developed in Scotland in 1999, it focuses on four key areas: situational awareness, decision making, task management, and teamwork skills. Each area provides examples of good and bad behaviors and creates an effective framework for a behavioral assessment on a 4-point scale [27]. This framework provides an instrument with which to appraise performance during various resource-management courses in anesthetic simulation [26]. The ANTS framework can also be used to train the local trainers, allowing the system to continue even after the initial training mission is complete and the visiting trainers return home.

The Society for Simulation in Healthcare defines fidelity as the degree to which the simulation replicates the real event and/or workplace, including the physical, psychological, and environmental elements [28]. In health care simulation, highfidelity refers to simulation experiences that are realistic and provide a high level of interactivity and realism for the learner.
High fidelity can be applied to many modes or methods of simulation such as human/standardized patients, manikins, task trainers, or virtual reality. Selecting the right simulator is based on objectives and needs assessments individualized to each country.

Although ANTS was designed initially to be used in the UK, where high-fidelity simulation has been shown to provide significant improvements in crisis situations, the framework is versatile enough to be applied to low-fidelity simulators with similar results. Indeed, it has been used in low-income countries such as Rwanda [29, 30, 31•]. Additional recommendations for effective implementation of the ANTS framework for simulation include (1) video replay to allow participants to reflect on their actions and facilitate further exploration of their cognitive processes, (2) small-group training to maximize time for class discussion and individual feedback, and (3) a minimum 2-day course for trainers [27].

Deficiencies in human factors contribute to $82 \%$ of preventable anesthesia errors $[32,33]$. Skelton et al. [31•] demonstrated improvement in ANTS practice through low-fidelity simulation in a low-income country, but additional studies are needed to identify and evaluate the influence of culture on teamwork and communication to better tailor educational programs to a country's needs. Using the TEAM scale, a validated tool for measuring behavior skills in emergency resuscitation, Perry et al. [34] observed lower scores in leadership and communication skills after a Neonatal Resuscitation Program in Honduras. Upon further evaluation, the authors noted that high power distances (social status differences), which reinforce an unequal power distribution, and a culture of collectivism, which values group loyalty, made communication difficult during debriefing. A male-biased medical hierarchy was also thought to affect the likelihood that female nurses would voice their concerns. Chung et al. advocates debriefing with a culture-sensitive interpretation of simulation-based learning to maximize benefit from debriefing sessions. [35]

When simulation occurs in the unit or on the floor, as opposed to within a simulation center, it is called in situ simulation [36]. This type of simulation can be used to train the entire staff, but it also helps to identify lapses in safe care for the patient. In low-resource environments, in situ simulation can be used to provide mobile experiences to practitioners across a vast geographical region or as a substitute for the high cost of developing a simulation center.

A simulation operations specialist (SOS) is an inclusive term that embodies many different roles within healthcare simulation operations, including simulation technician, simulation operations specialist, simulation multi-media/audio-visual specialist, or technology specialist [28]. Although many of these individuals design simulation activities, set up and break down the environment, and repair manikins, the Society of Simulation in Healthcare now offers an SOS certification. 
In several countries, SOSs must consider climate, power, theft, and safety or security risks. The versatility and adaptability of an SOS in overcoming difficulties can greatly contribute to the success of the simulation [37]. While the overriding goal should be to develop self-sustaining simulation systems in LMICs, at times, equipment must be transported from high-income countries to develop a center or to use in short-term training projects. Transportation, electrical/power supply, cost, and maintenance of the equipment while in country and upon departure need to be taken into account. During transport, high- and low-fidelity equipment must first pass through the customs and border security of the countries these equipment originate from, and often, these countries may require the submission of applications that disclose the type of equipment and its intended purpose. Generally, these documents include (1) certificate of donation, (2) packing list, (3) proforma invoice, and (4) certificate of conformity. After receiving these documents, the recipient may need to apply for government clearance such as the country's Food and Drug Administration certificates and tax exemptions for the academic and medical equipment. Usually, only after such government clearance is obtained by the receiving institution can the consignment be shipped to the country. Sending equipment by boat may be less expensive than by air, but this method must be planned well in advance as it may take more than 6 months for some equipment to arrive. In many instances, SOSs may choose to take equipment as a carry-on or a checked bag. Whether shipping or by air or by boat, weight is an issue, as one must consider the need for other maintenance tools and/or fuses. Electrical and power challenges that may be encountered include the need for plug convertors, surge protectors, and UPS (uninterrupted power supply) support to smooth out interruptions during power failures. These items may be found in some countries, but others need to be purchased in advance.

Working in a low-resource setting brings many challenges. A very noticeable one is cost. Complex and life-like computer-controlled manikins can cost twice as much as annual salaries for educators (e.g., Laerdal SimMan 3G is $\$ 80,000$ USD). A possible solution to help in low-resource settings is to work with vendor-partners, grants, government agencies, and philanthropic contributors. When trainers innovate their own programs through the development of 3D printing, reconditioning older manikins, or building skill-targeted scenarios around basic task-trainers, the objectives of the simulation can still be met.

Maintenance is also a challenge because most systems throughout simulation are reactive rather than proactive, meaning that responsible parties tend to repair broken equipment rather than using strong preventative maintenance programs [38]. A host of factors such as training time, professional development, and cost can contribute to this tendency. These challenges can be difficult to overcome in lowresource settings, and solutions should be strategized to plan for program sustainability. Training and professional development for equipment support are rare in countries that do not have distributors, sales, or networks of experts that can be called upon for help.

Many SOSs have a wealth of experience to identify how long chest skins, airways, or vessels will last or when they should be replaced based on timing or usage. Humidity, cleaning materials, and access to replacement parts are challenges to the upkeep of these trainers. To prolong the life of the training equipment, SOSs should spend equal time teaching maintenance and troubleshooting to improve the simulation clinical experiences.

\section{Current Developments}

Good quality educational programs are critical to solving the global anesthesia workforce crisis and improving access to life-saving health care. Simulation training is consistently associated with positive improvements in knowledge, skills, and behaviors when compared to no intervention and is at least as good as non-simulation instruction [39, 40]. However, studies of simulation training primarily take place in high-income countries that lack the cultural and logistical challenges faced in LMICs. For an education program to succeed, it must be tailored to the local environment. Many differences related to cultural factors, resources, and surgical needs exist even among LMICs [41]. Most LMICs experience what is known as an "education paradox" wherein health care workers in the areas that require the most training are unable to offer that training because they lack the time [41]. Even when trainers are available, essential resources and equipment are often lacking [42]. Studies on simulation models in LMICs are important for creating effective programs grounded in realistic and authentic clinical context that maximizes the limited time and resources [43].

The Johns Hopkins Global Alliance of Perioperative Professionals (JH-GAPP) collaborated with the Sierra Leone Ministry of Health and Sanitation to train nurse anesthetists nationwide using portable, low-cost, high-fidelity simulation equipment. An in situ simulation-based education program that reviewed clinical concepts critical for safe anesthesia care and utilized the RCDP methodology with locally adapted anesthesia scenarios was delivered to nurse anesthetist providers. This simulation system consisted of a spontaneously breathing model that allowed trainees an opportunity to execute management decisions as they transitioned between spontaneous ventilation, assisted manual ventilation, and synchronized and unsynchronized mechanical ventilation. JH-GAPP utilized two durable, low-cost $(\$ 15,000)$ Ingmar Medicine systems along with a SimMon vital sign simulation system (LCD monitor, \$600; Apple iPad, \$300; SimMon App, \$22.99) to train trainers on skills such as intubation and ventilator management. These trainers then traveled extensively with the 
simulation equipment and conducted regional trainings at district hospitals with 1-week simulation drills for regional participants. Follow-up refresher simulation trainings revealed considerable learning retention with respect to clinical knowledge and technical and nontechnical anesthesia skills. The results for these trainings are under review for publication.

Similarly, a training-of-trainers program using low-cost high-fidelity simulation was piloted in Tanzania based on the training model previously used in Sierra Leone. JH-GAPP collaborated with the Kilimanjaro Christian Medical Center (KCMC) in Tanzania to conduct this training with anesthesia providers from both Tanzania and Zambia in attendance. Simulations were designed to teach providers how to efficiently deliver inhalational anesthesia under routine conditions and challenging situations such as power failure and depletion of compressed oxygen. This training has been replicated for other anesthesia providers in Tanzania and Zambia multiple times.

In Tanzania, recognition by the government of the relevance and effectiveness of these anesthesia simulation trainings for various cadres of anesthesia providers has culminated in the establishment of two national medical simulation labs in Muhimbili and KCMC. In addition, the process of integrating simulation training into the formal anesthesia degree and diploma programs offered in Tanzania has been initiated. This simulation-based approach is being widely adopted in concert with the execution of the national surgical, obstetric, and anesthesia plan, and strategic investments in anesthesia equipment and supplies.

Next steps for sustainably scaling up training in Tanzania include plans for establishing regional simulation centers and mobile simulation training teams targeting rural health facilities. Hospitals are being strategically equipped with simulation equipment and locally appropriate anesthesia equipment such as the Universal Anesthesia Machine (UAM®). Regional practicum sites are being developed to greatly increase access to continuous simulation training and support in situ clinical mentorship of anesthesia providers at rural health centers in order to improve provider skills and optimize patient surgical outcomes.

\section{Future Directions}

Many professional societies and academic institutions have partnered with local governments and hospitals in LMICs to provide training through educational workshops, but limitations in time and budget make it difficult to maintain the integrity and quality of these training programs. Telesimulation is a novel concept that uses the internet to link simulators and teach procedural skills to instructors and trainees in different locations. One study showed that surgical skills improved after an 8-week telesimulation course that used a simple trainer box, webcam, and laptop to connect physicians in Canada and Botswana [44]. Telesimulation has also been used to teach a new intraosseous insertion technique to physicians in Botswana [45]. In anesthesia, telesimulation could be utilized for training procedures that range from epidural placement to regional techniques. A limitation of this modality is the availability and reliability of electricity and internet service. Telesimulation allows longer duration of training and follow-up, deliberate practice with real-time feedback, and demonstration of proper technique.

The idea of portable or mobile simulation is gaining traction in the surgical community and should be studied for its potential in anesthesia education as well [46]. Countries like Afghanistan and Liberia do not have an established anesthesia residency training program and thus rely on house officers, nurses, or anesthesia assistants to deliver anesthesia care, putting patients at significant risk for morbidity and mortality [42, 47]. The few available trained anesthesia providers gravitate toward urban areas, with very few serving rural areas. Linden et al. reports that there are 17 anesthesiologists for all of Uganda, which has a population of about 33 million [48]. Additionally, of the 14 district hospitals in Uganda, none had an anesthesiologist. Kenya has 120 anesthesiologists for a population of 32 million, but only 13 work in public hospitals; the remainder are in private practice in the capital, Nairobi [42]. These statistics emphasize the need for increased numbers of trained anesthesia providers and greater equity in their distribution. Expanded use of center-based and mobile simulation training can help reduce this unmet demand for anesthetic care by making opportunities for continuous training and skills remediation more accessible to physician and non-physician providers.

With practically no cost, mental imagery simulation also has the potential to enhance any anesthesia simulation training, or it can be used as a stand-alone program. Mental practice is a cognitive rehearsal of a task before its performance. The obvious limitation with mental imagery is the absence of physical practice to develop muscle memory, but Lim et al. found no difference in epidural anesthesia skill acquisition when anesthesia residents were randomized to low-fidelity haptic simulation or mental imagery training [49]. Conversely, RCDP is a simulation modality that has been shown to improve skill acquisition and retention through development of muscle memory and immediate feedback. Traditionally, simulation-based team training involves post-simulation debriefing. Hunt et al. first described RCDP in a study that showed improved pediatric resident resuscitation skills at an American institution [10]. A potential limiting factor with RCDP in LMICs is time owing to the number of cycles that may be required for a trainee to complete a simulation.

Debriefing has been identified as an essential component of health care simulation [50]. It consists of a facilitated 
conversation between the participant and trainer that takes place after critical events and simulations. Its goal is to help the trainee to analyze his/her thought process and actions to improve performance [51]. In areas with limited time, resources, and trained professionals, it becomes imperative to uphold certain standards when creating sustainable training programs. One aspect that warrants further study and development in LMICs is the use of tools to evaluate the instructor's debriefing competence. The Debriefing Assessment for Simulation in Healthcare (DASH) is one such method developed by Brett-Fleegler et al. which was shown to have good reliability and validity for evaluating the quality of health care simulation debriefings [52].
Development of successful educational programs in LMICs hinges on several factors, including collaboration with local providers and governments and development of appropriate curricula that take into account the needs of the recipient country [53]. An effective simulation curriculum design maximizes learning and ultimately patient safety in LMICs. However, there are very few examples of appropriate studies that demonstrate progress or identify which new or existing simulation models are the most effective (Table 1). It is imperative that we increase collaboration and effort toward global goals and standards for simulation training in LMICs. Otherwise, limited knowledge is passed on to trainees, creating a flawed training system and compounding errors in anesthesia practice $[54,55]$, with the potential of patient harm.

Table 1 Simulation modalities and skills described in low- and middle-income countries (LMICs)

\begin{tabular}{|c|c|c|c|c|c|}
\hline Author and year & $\begin{array}{l}\text { Primary } \\
\text { country }\end{array}$ & Simulation modality & $\begin{array}{l}\text { Skill and/or competence } \\
\text { domain }\end{array}$ & No. of participants & Equipment \\
\hline \multicolumn{6}{|l|}{ Africa } \\
\hline Bergman et al. 2008 [56] & Tanzania & $\begin{array}{l}\text { Full-scale simulation } \\
\text { and task-training } \\
\text { device to teach } \\
\text { technical skills }\end{array}$ & $\begin{array}{l}\text { Trauma resuscitation: } \\
\text { cardiac life support } \\
\text { and intubation }\end{array}$ & 20 & $\begin{array}{l}\text { Basic manikins and } \\
\text { equipment available } \\
\text { at local facilities }\end{array}$ \\
\hline Chima et al. 2017 [8••] & Sierra Leone & $\begin{array}{l}\text { In situ, full-scale } \\
\text { simulation to identify } \\
\text { performance gaps }\end{array}$ & $\begin{array}{l}\text { Obstetrics: managing } \\
\text { complications with } \\
\text { regional and general } \\
\text { anesthesia }\end{array}$ & 21 & $\begin{array}{l}\text { Universal Anesthesia } \\
\text { Machine (UAM) and } \\
\text { lung simulators }\end{array}$ \\
\hline Livingston et al. 2014 [57] & Rwanda & $\begin{array}{l}\text { Full-scale simulation } \\
\text { and task-training } \\
\text { device to teach } \\
\text { technical and } \\
\text { nontechnical skills }\end{array}$ & $\begin{array}{l}\text { Obstetric anesthesia } \\
\text { skills and knowledge }\end{array}$ & 90 & $\begin{array}{l}\text { Low-fidelity simulators } \\
\text { (intubation heads, } \\
\text { resuscitation dolls, } \\
\text { and simple } \\
\text { task-trainers) }\end{array}$ \\
\hline Mikrogianakis et al. 2011 [45] & Botswana & $\begin{array}{l}\text { Telesimulation to teach } \\
\text { technical skills }\end{array}$ & $\begin{array}{l}\text { Resuscitation: } \\
\text { intraosseous insertion } \\
\text { technique }\end{array}$ & 22 & $\begin{array}{l}\text { Telesimulation using } \\
\text { standard television, } \\
\text { simulator camera, } \\
\text { laptop, and trainer } \\
\text { box }\end{array}$ \\
\hline Skelton et al. 2016 [31] & Rwanda & $\begin{array}{l}\text { Full-scale simulation to } \\
\text { teach nontechnical } \\
\text { skills }\end{array}$ & $\begin{array}{l}\text { Anesthesia nontechnical } \\
\text { skills (ANTS): } \\
\text { hypotension and } \\
\text { anaphylaxis during } \\
\text { C-section }\end{array}$ & 20 & $\begin{array}{l}\text { Laerdal airway manikin, } \\
\text { operating theater } \\
\text { equipment, an } \\
\text { anesthesia gas } \\
\text { machine (no longer in } \\
\text { service) }\end{array}$ \\
\hline Taché et al. 2009 [3] & Tanzania & $\begin{array}{l}\text { Task-training device to } \\
\text { teach technical skills }\end{array}$ & $\begin{array}{l}\text { Anesthesia technical } \\
\text { skills: intubation }\end{array}$ & 36 & $\begin{array}{l}\text { Adult intubation } \\
\text { manikins }\end{array}$ \\
\hline \multicolumn{6}{|l|}{ Americas } \\
\hline Taira et al. 2016 [58] & Nicaragua & $\begin{array}{l}\text { Full-scale simulation to } \\
\text { teach technical skills }\end{array}$ & $\begin{array}{l}\text { Resuscitation: cardiac } \\
\text { arrest }\end{array}$ & 13 & Low-tech simulator \\
\hline Urbano et al. 2009 [59] & Honduras & $\begin{array}{l}\text { Full-scale simulation } \\
\text { and task-training } \\
\text { device to teach } \\
\text { technical skills }\end{array}$ & $\begin{array}{l}\text { Resuscitation: CPR, } \\
\text { airway and vascular } \\
\text { access, arrhythmias }\end{array}$ & 24 & Laerdal manikins \\
\hline \multicolumn{6}{|l|}{ Europe } \\
\hline Artyomenko et al. 2017 [23] & Ukraine & $\begin{array}{l}\text { Full-scale simulation } \\
\text { and task-training }\end{array}$ & $\begin{array}{l}\text { Obstetrics: CPR, airway } \\
\text { and vascular access }\end{array}$ & 109 & $\begin{array}{l}\text { Basic and high-fidelity } \\
\text { manikins }\end{array}$ \\
\hline
\end{tabular}

$C P R$, cardiopulmonary resuscitation 


\section{Conclusion}

Good quality educational programs are critical to filling the gap in the global anesthesia workforce. Simulation-based learning may be an integral part of achieving this goal in LMICs. However, many challenges and barriers can be encountered when developing and establishing anesthesia curricula in LMICs, where the needs and capacity vary significantly from one country to another. Currently, the literature is quite limited with regard to establishment of these anesthesia training teaching tools. As such, ample opportunity exists for additional research to identify the best simulation method for each country's unique needs and capabilities.

Acknowledgments The authors of this article wish to disclose that in the past, they have received funding from Gradian Health Systems, Inc. for the development of anesthesia training programs in Sierra Leone and Tanzania. The authors of this study are also members of the Johns Hopkins Global Alliance of Perioperative Professionals.

\section{Compliance with Ethical Standards}

Conflict of Interest Howard Nelson-Williams has received research funding from Gradian Health Systems, Inc., as noted above in the Acknowledgments, as well as compensation from Gradian Health Systems for service as a consultant.

John Sampson has received research funding from Gradian Health Systems, Inc., as noted above in the Acknowledgments.

The following co-authors Oleg Turkot, Michael C. Banks, Seung Woo Lee, Adam Dodson, Shirley Duarte, Mwemezi Kaino and Serkan Toy declare that they have not received any research funding and do not have a conflict of interest of any kind.

Human and Animal Rights and Informed Consent This article does not contain any studies with human or animal subjects performed by any of the authors.

Open Access This article is distributed under the terms of the Creative Commons Attribution 4.0 International License (http:// creativecommons.org/licenses/by/4.0/), which permits unrestricted use, distribution, and reproduction in any medium, provided you give appropriate credit to the original author(s) and the source, provide a link to the Creative Commons license, and indicate if changes were made.

Publisher's Note Springer Nature remains neutral with regard to jurisdictional claims in published maps and institutional affiliations.

\section{References}

Papers of particular interest, published recently, have been highlighted as:

- Of importance

•- Of major importance

1. Meara JG, Leather AJ, Hagander L, Alkire BC, Alonso N, Ameh EA, et al. Global surgery 2030: evidence and solutions for achieving health, welfare, and economic development. Lancet. 2015;386: 569-624. https://doi.org/10.1016/S0140-6736(15)60160-X.
2. The World Bank. New country classifications by income level: 2016-2017. 2016. Available from https://blogs.worldbank.org/ opendata/new-country-classifications-2016. Accessed 13 Sept 2018.

3. Taché S, Mbembati N, Marshall N, Tendick F, Mkony C, O'Sullivan P. Addressing gaps in surgical skills training by means of low-cost simulation at Muhimbili University in Tanzania. Hum Resour Health. 2009;7:64. https://doi.org/10. 1186/1478-4491-7-64.

4. Holmer H, Shrime MG, Riesel JN, Meara JG, Hagander L. Towards closing the gap of the global surgeon, anaesthesiologist, and obstetrician workforce: thresholds and projections towards 2030. Lancet. 2015;385(Suppl 2):S40. https://doi.org/10.1016/S0140-6736(15) 60835-2.

5. Holmer H, Lantz A, Kunjumen T, Finlayson S, Hoyler M, Siyam A, et al. Global distribution of surgeons, anaesthesiologists, and obstetricians. Lancet Glob Health. 2015;3(Suppl 2):S9-11. https://doi. org/10.1016/S2214-109X(14)70349-3.

6. Livingston P, Bailey J, Ntakiyiruta G, Mukwesi C, Whynot S, Brindley P. Development of a simulation and skills centre in East Africa: a Rwandan-Canadian partnership. Pan Afr Med J. 2014;17: 315. https://doi.org/10.11604/pamj.2014.17.315.4211.

7. Derbew M. COSECSA collaborates to address surgical shortages in sub-Saharan Africa. 2018. Available from http://bulletin.facs.org/ 2018/05/cosecsa-collaborates-to-address-surgical-shortages-insub-saharan-africa/. Accessed 31 Aug 2018.

8.• Chima AM, Koka R, Lee B, Tran T, Ogbuagu OU, NelsonWilliams $\mathrm{H}$, et al. Medical simulation as a vital adjunct to identifying clinical life-threatening gaps in austere environments. J Natl Med Assoc. 2018;110:117-23. https://doi.org/10.1016/j.jnma. 2017.12.003 The only article using simulation scenarios to assess knowledge and skills gaps in Africa and other lowincome countries. Describes using spontaneous breathing simulation model which is the most common airway management technique in low-resource countries.

9. McGaghie WC, Issenberg SB, Petrusa ER, Scalese RJ. A critical review of simulation-based medical education research: 2003 2009. Med Educ. 2010;44:50-63. https://doi.org/10.1111/j.13652923.2009.03547.x.

10. Hunt EA, Duval-Arnould JM, Nelson-McMillan KL, Bradshaw JH, Diener-West M, Perretta JS, et al. Pediatric resident resuscitation skills improve after "rapid cycle deliberate practice" training. Resuscitation. 2014;85:945-51. https://doi.org/10.1016/j. resuscitation.2014.02.025.

11. Magee MJ, Farkouh-Karoleski C, Rosen TS. Improvement of immediate performance in neonatal resuscitation through rapid cycle deliberate practice training. J Grad Med Educ. 2018;10:192-7. https://doi.org/10.4300/JGME-D-17-00467.1.

12. Taras J, Everett T. Rapid cycle deliberate practice in medical education - a systematic review. Cureus. 2017;9:e1180. https://doi.org/ 10.7759 /cureus. 1180 .

13. Knowles MS, Holton EF, Swanson RA. A theory of adult learning: andragogy. The adult learner: the definitive classic in adult education and human resource development. London: Elsevier; 2005. p. 35-72.

14. Zigmont JJ, Kappus LJ, Sudikoff SN. Theoretical foundations of learning through simulation. Semin Perinatol. 2011;35:47-51. https://doi.org/10.1053/j.semperi.2011.01.002.

15. Mezirow J. Learning as transformation: critical perspectives on a theory in progress. 2000. Available from https://eric.ed.gov/?id= ED448301. Accessed 23 Sept 2018.

16. Clapper TC. Beyond Knowles: what those conducting simulation need to know about adult learning theory. Clin Simul Nurs. 2010;6: e7-e14.

17. Abrahamson S, Denson JS, Wolf RM. Effectiveness of a simulator in training anesthesiology residents. J Med Educ. 1969;44:515-9. 
18. Lane JL, Slavin S, Ziv A. Simulation in medical education: a review. Simul Gaming. 2001;32:297-314.

19. Engum SA. Do you know your students' basic clinical skills exposure? Am J Surg. 2003;186:175-81.

20. Okuda Y, Bryson EO, DeMaria S, et al. The utility of simulation in medical education: what is the evidence? Mt Sinai J Med. 2009;76: 330-43.

21. Cook DA, Hatala R, Brydges R, Zendejas B, Szostek JH. Technology-enhanced simulation for health professions education: a systematic review and meta-analysis. JAMA. 2011;306(9):987-8.

22. Cook DA, Brydges R, Hamstra SJ, Zendejas B, Szostek JH, Wang AT. Comparative effectiveness of technology-enhanced simulation versus other instructional methods- a systematic review and metaanalysis. Sim Healthcare. 2012;7:308-20.

23. Artyomenko VV, Nosenko VM. Anaesthesiologists' simulation training during emergencies in obstetrics. Rom J Anaesth Intensive Care. 2017;24:37-40. https://doi.org/10.21454/rjaic. 7518.241.dym The only recent article on simulation training in a low middle income country in Europe.

24. Core competencies for interprofessional collaborative practice. 2011. Available from https://www.aacom.org/docs/default-source/ insideome/ccrpt05-10-11.pdf?sfvrsn=77937f97_2. Accessed 9 Oct 2018.

25. Scavone BM, Toledo P, Higgins N, Wojciechowski K, McCarthy RJ. A randomized controlled trial of the impact of simulation-based training on resident performance during a simulated obstetric anesthesia emergency. Simul Healthc. 2010;5:320-4. https://doi.org/10. 1097/SIH.0b013e3181e602b3.

26. Bhagwat M. Simulation and anaesthesia. Indian J Anaesth. 2012;56:14-20. https://doi.org/10.4103/0019-5049.93338.

27. Flin R, Patey R, Glavin R, Maran N. Anaesthetists' non-technical skills. Br J Anaesth. 2010;105:38-44. https://doi.org/10.1093/bja/ aeq134.

28. Lopreiato JO, Downing D, Gammon W, Lioce L, Sittner B, Slot V, et al. Healthcare simulation dictionary. Rockville: Agency for Healthcare Research and Quality; 2016.

29. Yee B, Naik VN, Joo HS, Savoldelli GL, Chung DY, Houston PL, et al. Nontechnical skills in anesthesia crisis management with repeated exposure to simulation-based education. Anesthesiology. 2005; 103:241-8.

30. Gu Y, Witter T, Livingston P, Rao P, Varshney T, Kuca T, et al. The effect of simulator fidelity on acquiring non-technical skills: a randomized non-inferiority trial. Can J Anaesth. 2017;64:1182-93. https://doi.org/10.1007/s12630-017-0973-2.

31. Skelton T, Nshimyumuremyi I, Mukwesi C, Whynot S, Zolpys L, Livingston P. Low-cost simulation to teach anesthetists' nontechnical skills in Rwanda. Anesth Analg. 2016;123:474-80. https://doi.org/10.1213/ANE.0000000000001434 An excellent resource on implementation of nontechnical skills in subSaharan Africa.

32. Cooper JB, Newbower RS, Long CD, McPeek B. Preventable anesthesia mishaps: a study of human factors. 1978. Qual Saf Health Care 2002; 11: 277-282.

33. Williamson JA, Webb RK, Sellen A, Runciman WB, Van der Walt $\mathrm{JH}$. The Australian Incident Monitoring Study. Human failure: an analysis of 2000 incident reports. Anaesth Intensive Care. 1993;21: 678-83.

34. Perry MF, Seto TL, Vasquez JC, Josyula S, Rule ARL, Rule DW, et al. The influence of culture on teamwork and communication in a simulation-based resuscitation training at a community hospital in Honduras. Simul Healthc. 2018;13:363-70. https://doi.org/10. 1097/SIH.0000000000000323.

35. Chung HS, Dieckmann P, Issenberg SB. It is time to consider cultural differences in debriefing. Simul Healthc. 2013;8:166-70. https://doi.org/10.1097/SIH.0b013e318291d9ef.
36. Pratt SD. Focused review: simulation in obstetric anesthesia. Anesth Analg. 2012;114:186-90. https://doi.org/10.1213/ANE. 0b013e3182377bbc.

37. Alinier G, Dodson A. International perspectives on the role of the simulation operations specialist. In: Gantt LT, Young HM, editors. Healthcare simulation: a guide for operations specialists. Hoboken: Wiley; 2015.

38. Grimes CE, Bowman KG, Dodgion CM, Lavy CB. Systematic review of barriers to surgical care in low-income and middleincome countries. World J Surg. 2011;35:941-50. https://doi.org/ 10.1007/s00268-011-1010-1.

39. Lorello GR, Cook DA, Johnson RL, Brydges R. Simulationbased training in anaesthesiology: a systematic review and meta-analysis. Br J Anaesth. 2014;112:231-45. https://doi.org/10. 1093/bja/aet414.

40. Cook DA, Hatala R, Brydges R, Zendejas B, Szostek JH, Wang AT, et al. Technology-enhanced simulation for health professions education: a systematic review and meta-analysis. JAMA. 2011;306: 978-88. https://doi.org/10.1001/jama.2011.1234.

41. Morriss WW, Milenovic MS, Evans FM. Education: the heart of the matter. Anesth Analg. 2018;126:1298-304. https://doi.org/10. 1213/ANE.0000000000002653.

42. Dubowitz G, Detlefs S, McQueen KA. Global anesthesia workforce crisis: a preliminary survey revealing shortages contributing to undesirable outcomes and unsafe practices. World J Surg. 2010;34: 438-44. https://doi.org/10.1007/s00268-009-0229-6.

43. Kneebone RL, Nestel D, Vincent C, Darzi A. Complexity, risk and simulation in learning procedural skills. Med Educ. 2007;41:808 14. https://doi.org/10.1111/j.1365-2923.2007.02799.x.

44. Okrainec A, Henao O, Azzie G. Telesimulation: an effective method for teaching the fundamentals of laparoscopic surgery in resource-restricted countries. Surg Endosc. 2010;24:417-22. https://doi.org/10.1007/s00464-009-0572-6.

45. Mikrogianakis A, Kam A, Silver S, Bakanisi B, Henao O, Okrainec A, et al. Telesimulation: an innovative and effective tool for teaching novel intraosseous insertion techniques in developing countries. Acad Emerg Med. 2011;18:420-7. https://doi.org/10.1111/j.15532712.2011.01038.x.

46. Shaikh FM, Hseino H, Hill AD, Kavanagh E, Traynor O. Mobile surgical skills education unit: a new concept in surgical training. Simul Healthc. 2011;6:226-30. https://doi.org/10.1097/SIH. 0b013e318215da5e.

47. Glenshaw M, Madzimbamuto FD. Anaesthesia associated mortality in a district hospital in Zimbabwe: 1994 to 2001. Cent Afr J Med. 2005;51:39-44.

48. Linden AF, Sekidde FS, Galukande M, Knowlton LM, Chackungal S, McQueen KA. Challenges of surgery in developing countries: a survey of surgical and anesthesia capacity in Uganda's public hospitals. World J Surg. 2012;36:1056-65. https://doi.org/10.1007/ s00268-012-1482-7.

49. Lim G, Krohner RG, Metro DG, Rosario BL, Jeong JH, Sakai T. Low-fidelity haptic simulation versus mental imagery training for epidural anesthesia technical achievement in novice anesthesiology residents: a randomized comparative study. Anesth Analg. 2016;122:1516-23. https://doi.org/10.1213/ANE. 0000000000001260 .

50. Issenberg SB, McGaghie WC, Petrusa ER, Lee GD, Scalese RJ. Features and uses of high-fidelity medical simulations that lead to effective learning: a BEME systematic review. Med Teach. 2005;27:10-28. https://doi.org/10.1080/ 01421590500046924.

51. Rudolph JW, Simon R, Raemer DB, Eppich WJ. Debriefing as formative assessment: closing performance gaps in medical education. Acad Emerg Med. 2008;15:1010-6. https://doi.org/10.1111/j. 1553-2712.2008.00248.x. 
52. Brett-Fleegler M, Rudolph J, Eppich W, Monuteaux M, Fleegler E, Cheng A, et al. Debriefing assessment for simulation in healthcare: development and psychometric properties. Simul Healthc. 2012;7:288-94. https://doi.org/10.1097/SIH. 0b013e3182620228.

53. Dubowitz G, Evans FM. Developing a curriculum for anaesthesia training in low- and middle-income countries. Best Pract Res Clin Anaesthesiol. 2012;26:17-21. https://doi.org/10.1016/j.bpa.2012. 02.004 .

54. Lundeg G, Baric A, Pescod DC, Pescod K. Anesthesia development in Mongolia: strengthening anesthesia practice in Mongolia through education and continuing professional development. Anesth Analg. 2018;126:1287-90. https://doi.org/10.1213/ANE. 0000000000002566 .

55. Khan FA, Merry AF. Improving anesthesia safety in low-resource settings. Anesth Analg. 2018;126:1312-20. https://doi.org/10. 1213/ANE.0000000000002728.

56. Bergman S, Deckelbaum D, Lett R, Haas B, Demyttenaere S, Munthali $\mathrm{V}$, et al. Assessing the impact of the trauma team training program in Tanzania. J Trauma. 2008;65:879-83. https://doi.org/ 10.1097/TA.0b013e318184a9fe.

57. Livingston P, Evans F, Nsereko E, Nyirigira G, Ruhato P, Sargeant $\mathrm{J}$, et al. Safer obstetric anesthesia through education and mentorship: a model for knowledge translation in Rwanda. Can J Anaesth. 2014;61:1028-39. https://doi.org/10.1007/s12630-014-0224-8.

58. Taira BR, Orue A, Stapleton E, Lovato L, Vangala S, Tinoco LS, et al. Impact of a novel, resource appropriate resuscitation curriculum on Nicaraguan resident physician's management of cardiac arrest. J Educ Eval Health Prof. 2016:13-25. https://doi.org/10. 3352/jeehp.2016.13.25.

59. Urbano J, Matamoros MM, Lopez-Herce J, Carrillo AP, Ordonez F, Moral R, et al. A paediatric cardiopulmonary resuscitation training project in Honduras. Resuscitation. 2010;81:472-6. https://doi.org/ 10.1016/j.resuscitation.2010.01.007.

60. Kempthorne P, Morriss WW, Mellin-Olsen J, Gore-Booth J. The WFSA global anesthesia workforce survey. Anesth Analg. 2017;125(3):981-990. https://doi.org/10.1213/ANE. 0000000000002258 